\title{
The effect of competition on learning in games
}

\author{
Nergiz Ercil Cagiltay ${ }^{a}$, Erol Ozcelik ${ }^{b}{ }^{*}$, Nese Sahin Ozcelik ${ }^{c}$ \\ ${ }^{a}$ Department of Software Engineering, Atilim University, Ankara, 06836, Turkey \\ b Department of Computer Engineering, Atilim University, Ankara, 06836, Turkey \\ ${ }^{\mathrm{c}}$ Computer Technology and Information Systems, Bilkent University, Ankara, 06800, Turkey
}

\section{A R T I C L E I N F O}

\section{Article history:}

Received 22 November 2014

Received in revised form

31 March 2015

Accepted 2 April 2015

Available online 13 April 2015

\section{Keywords:}

Interactive learning environments

Post-secondary education

\begin{abstract}
A B S T R A C T
Today serious games are having an important impact on areas other than entertainment. Studies show that serious games have a potential of creating learning environments to better reach the educational and training goals. The game design characteristics and game elements are need to be explored in detail for increasing the expected benefits of the gaming environments. In this study, the effect of competition, one of the design elements of game environments, on learning is analyzed experimentally. The study is conducted with 142 students. The results of this study show that when a competition environment is created in a serious game, motivation and post-test scores of learners improve significantly. The results of this study are expected to guide the serious game designers for improving the potential benefits of serious games.
\end{abstract}

๑) 2015 Elsevier Ltd. All rights reserved.

\section{Introduction}

Today serious games, games having purposes other than entertainment, are being used in several areas such as training, education, and health. However, nowadays these games are blamed to be more like drill and practice software than entertaining and engaging game play (van Eck, 2006). In order to improve the benefits of serious games, one needs to understand their design characteristics and control these characteristics according to educational or training purposes as well as the behaviors and expectations of the learner groups. In that sense, serious game design characteristics need to be analyzed carefully and systematically.

Several game characteristics such as uncertainty, challenge, feedback, fantasy, cooperation, and competition have been studied by several researchers (e.g., Malone \& Lepper, 1987). Many other characteristics can be added to this list. Understanding each of these elements and their effect on the game-based learning environments may improve the benefits of these games. On the other hand, there has been little empirical research examining the individual game characteristics on learning (Vandercruysse, Vandewaetere, Cornillie, \& Clarebout, 2013) and how the games should be designed for facilitating learning (Dondlinger, 2007). In this study, competition, which is classified as a characteristic of a serious game, is explored. An empirical study is conducted to understand the effect of competition on players' learning performance in serious games.

\section{Serious game design elements}

Based on different design perspectives and characteristics, the level of involvement, concentration, flow, learning, engagement and/or skill improvements through the game play may vary. In the scope of game-play, several design elements such as uncertainty, goals, challenge, feedback, learner control, competition, cooperation, fantasy, interactivity, flexibility, and fairness to have been explored in the literature to improve the benefits of games (Hong et al., 2009; Malone \& Lepper, 1987). In our earlier study (Ozcelik, Cagiltay, \& Ozcelik, 2013) we have conducted a research to understand the effect of uncertainty on learning in games. According to the results of this study, uncertainty enhances learning and has positive relation with motivation (Ozcelik et al., 2013). Results indicate that as motivation increases, learners tend to devote more time on answering the questions and to have superior accuracy in these questions (Ozcelik et al., 2013).

\footnotetext{
* Corresponding author. Tel.: +90 312586 8793; fax: +90 3125868091.

E-mail address: erol.ozcelik@atilim.edu.tr (E. Ozcelik).
} 
Juul (2005) proposes six necessary and sufficient features for games: (i) rules, (ii) variable and quantifiable outcomes, (iii) value assigned to outcomes, (iv) player effort to influence outcomes, (v) player attached to outcomes, and (vi) negotiable consequences of activities. Studies show that in order to guide the player reaching the game objectives, the goals of the game that the player required to reach and the rules of the game that the player should follow need to be provided explicitly (Csikszentmihalyi, 1990; Johnson \& Wiles, 2003; Pagulayan, Keeker, Wixon, Romero, \& Fuller, 2003) early in the game (Federoff, 2002) such as in the introduction or briefings of the game (Pagulayan et al., 2003). Otherwise, the player may be lost in the game and it may be hard to understand the players' learning performance through the game play (Dempsey, Lucassen, Haynes, \& Casey, 1996). Goal directed activities improve the flow experience of the players (Csikszentmihalyi, 1990). Additionally, when tasks have clear goals, there is a possible concentration in a game play (Sweetser \& Wyeth, 2005). Besides, feedback is another important characteristic that affects the game play. According to Malone (1981), feedback helps players to understand their performance in the game and to provide information about their success or failure. Studies also report that games should provide an immediate feedback for the player actions (Desurvire, Caplan, \& Toth, 2004; Johnson \& Wiles, 2003) in an appropriate way (Csikszentmihalyi, 1990) and should reward players on their progress in the game (Federoff, 2002; Pagulayan et al., 2003). Additionally, players should also be informed about their low performance and right directions (Gee, 2004). Researchers also report that challenge is another important element of a game design (Malone, 1981; Malone \& Lepper, 1987; Rouse, 2005; Sweetser \& Wyeth, 2005). According to the flow theory presented by Csikszentmihalyi (1975), the challenge in a game is closely related to the skills of the player. Hence, the game should be designed by considering the skill levels of the players. Control is another important component of a game which refers to the openness of the system to allow manipulations by the player (Federoff, 2002; Pagulayan et al., 2003; Pavlas, Bedwell, Wooten, Heyne, \& Salas, 2009). Control is the degree to which a learner has the power to make changes in the game environment (Pavlas et al., 2009). Similarly, some fantasy elements in the game design could also be considered another group of factors for creating effective games (Cruickshank \& Telfer, 1980; Lepper \& Cordova, 1992). Fantasy element, when used in serious games, may craft engaging and instructional challenges (Iuppa \& Borst, 2007; Lepper \& Malone, 1987; Parker \& Lepper, 1992).

Researchers report that the game design features through creating interaction between players such as competition and cooperation are critical elements for effective games (Andresen \& Ahdell, 2002; Dondlinger, 2007). "Competition is goal-oriented, directed towards achieving one's own goals even though this may have a negative effect on other competitors" (Hong et al., 2009, p. 5). Several different forms of competition such as team competition, competition between user and computer, competition against oneself, chance and time (Vandercruysse et al., 2013) have been defined for computer games. Several benefits of competition in games have been reported in the literature. For instance competition is regarded as a well structured learning activity that has the potential to draw attention and excitement of students (Cheng, Wu, Liao, \& Chan, 2009). Competition is considered as a useful technique to motivate individuals to learn (Julian \& Perry, 1967; Malone \& Lepper, 1987; Nemerow, 1996; Yu, 2000). For instance, van Eck and Dempsey (2002) report that competition may motivate the students extrinsically and as a result students may put more effort on current tasks. Pareto, Haake, Lindström, Sjödén, and Gulz (2012) also argue that competitive activities motive learners to play the game. Similarly, competitions enhance learning and cooperation among students (Battisti, Boato, Carli, \& Neri, 2011; Burguillo, 2010). Atanasijevic-Kunc, Logar, Karba, Papic, and Kos (2011) suggest that competition in games stimulate the interest of students and increases the efficiency of the learning process.

On the other hand, there are some concerns on excessive competitive activities which may cause negative influences on learning such as increasing anxiety, impeding performance on tasks, diminishing empowerment and responsibility for learning (Kohn, 1992). According to Shaffer (2006) competition is not an essential game design element. Similarly, Vandercruysse et al. (2013) found that computation is not significantly related to students' learning gains and only partly related to students' motivation.

Hence, the competitive game environments need to be explored in detail to better understand its effect on learning. Accordingly, we experimentally explored competition to examine its effect on learning in games. For this purpose, motivation, post-test scores, accuracy in the game, duration spent on reading statements and providing responses in the game were evaluated as measures in our serious game implementation. A game was developed to teach conceptual database modeling concepts by using entity-relationship (ER) diagrams, which are used for data modeling in relational databases. Two versions of the game were developed. One included competition and the other included no competition. Half of the randomly selected participants were assigned to the competition condition and the other half were assigned to the control condition.

\section{Research methodology}

\subsection{Participants}

The participants of this study were 142 undergraduate students (62 female and 80 male) from computer engineering, software engineering, and information systems engineering departments in Atilim University. The range of their age was between 20 and 28 years $(M=22.58, S D=1.64)$.

\subsection{Materials}

In this study several materials such as prior knowledge test, the game itself and a Turkish version (Acar, 2009) of the instructional materials motivation survey (IMMS) (Keller, 1993) were used. These materials are described in detail below.

\subsubsection{Prior knowledge test}

A prior knowledge test was administered in order to examine whether the competition and the control group differed in prior knowledge of the database concepts covered in the game, because research studies have shown that prior knowledge of participants may influence their performance in games (e.g., Lee \& Chen, 2009). The test includes five statements such as "I know how to read entity-relationship diagrams" in which participants needed to rate subjectively their knowledge on a scale from 1 (associated with "I know very little") to 5 (associated with "I know very much"). The prior knowledge test score was computed by taking the sum of the given five responses. 


\subsubsection{Post-test}

The post-test contained six questions. In the matching question, participants were required to match an item (e.g. "Author") on the given ER diagram with its concept name (e.g. "Entity"). The second and third questions were of fill-in-the-blank type. For a given ER diagram, students were asked to fill the blanks with appropriate word(s). An example item was "Write is a (n) ... ... kind of relation" where the correct answer was "many-to-many". The fourth and the fifth questions were of true-false type. An example of a true-false question is "An author can write many book" and the answer should be "True". The matching, fill-in-the-blank and true-false type questions included 5, 8, and 16 items, respectively. The last question required participants to draw an ER diagram for given requirements of a case.

\subsubsection{The game}

This drill \& practice game was designed to present conceptual database modeling concepts taught in database courses in higher education. The content of the game was adapted from Ozcelik et al. (2013). All participants were novice to the subject matter covered in the game. Therefore, they had equal opportunities to win the game (Hong et al., 2009). The goal of the users was to collect 336 points. In order to challenge the players, the following plot was presented: There had just been an attack on the nation's database system. Players needed to reveal and understand the secret symbols to ensure the security of the database. Actually these secret symbols were the concepts to be taught. The learners were presented 21 true-false statements in a game format. Firstly, players needed to roll two dices by clicking a button. Second, an ER diagram and a statement (e.g., "Author" and "Book" are entities) about the ER diagram was shown on the screen. Learners responded to the questions by checking a radio button with two choices: true and false. Half of the statements were true, and half were false. A feedback including whether the response was correct or incorrect as well as the explanation of the correct answer was shown after the response of the learner. By pressing the right arrow button, the next question appeared.

There existed a chance-based uncertainty in the game. Participants earned ten points plus the total of the two dices if their response was correct. Their points were subtracted by the total of the dices if the response was incorrect. All of the collected points were lost if both of the dice were one (Howard-Jones \& Demetriou, 2009). Participants could see how many points they earned or lost from the current question, as well as their total points.

For this study, two versions of the game were developed. The first version was developed with the competition option. In this version, as seen from Fig. 1, all the participants were connected to the gaming environment and they were able to see all current players' scores, ranking, and nick names in the right panel of the game interface in real-time. In the current study, each individual contests with the other participants simultaneously where each individual is an independent player (Vandercruysse et al., 2013). Participants were not allowed to work collaboratively. Learners can play the game concurrently without waiting their turn.

As seen from Fig. 2, in the second version of the game environment this list is left as empty. In other words, in the second version of the game, the player is not able to follow the other players' scores, ranking and nick names.

\subsubsection{Instructional materials motivation survey}

In order to assess motivation of participants toward the instructional materials that they have studied, a Turkish version (Acar, 2009) of the instructional materials motivation survey (IMMS) (Keller, 1993) was used. The survey consisted of 36 statements (e.g., "The content of this course is relevant to my interest") to be rated about the learning materials using a 5-point Likert-type scale ranging from 1 ("completely not true") to 5 ("completely true") with four subscales: attention, relevance, confidence, and satisfaction in accordance with the ARCS Model (Keller, 1983).

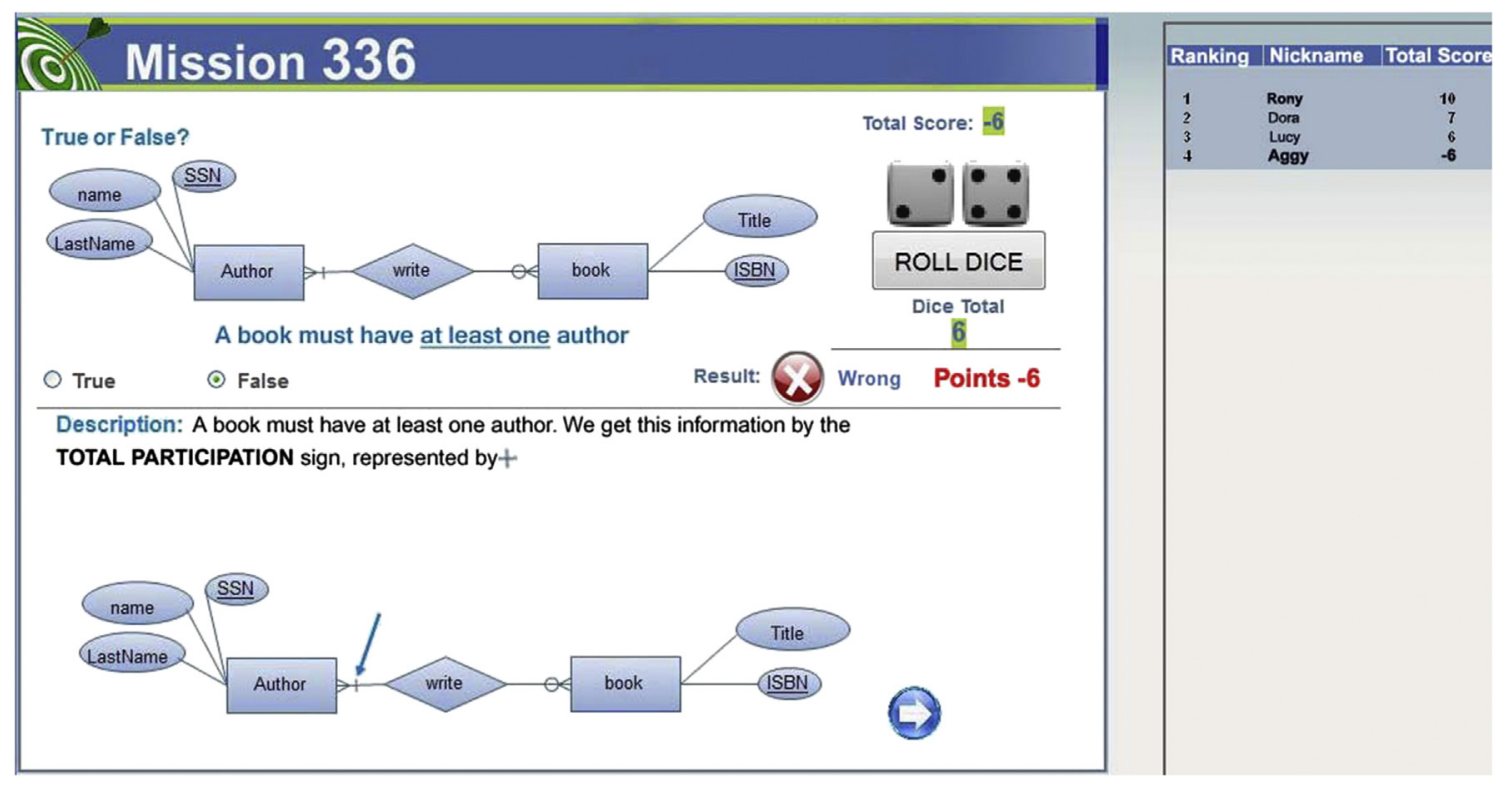

Fig. 1. A screenshot of the game that includes competition. 


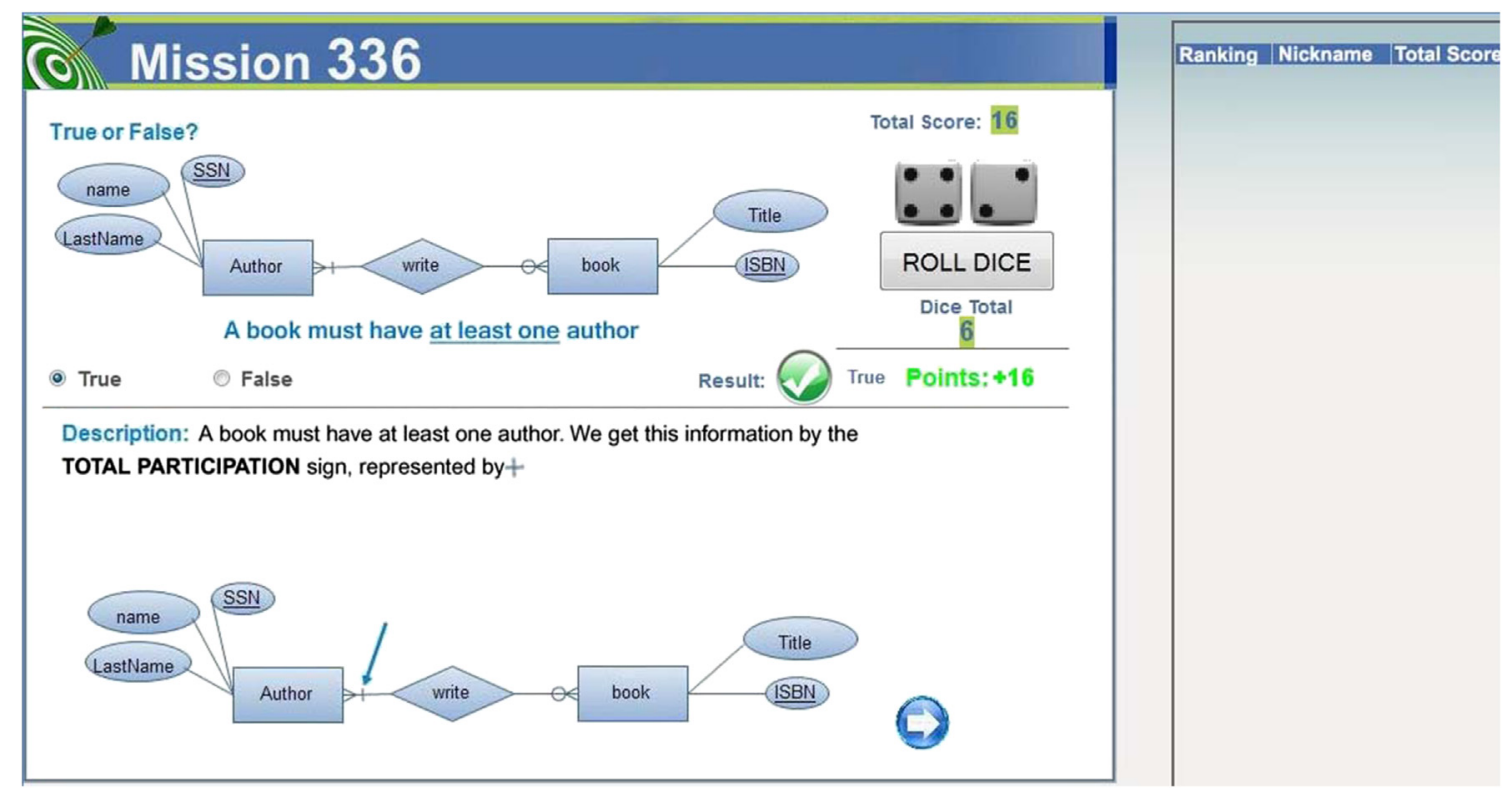

Fig. 2. A screenshot of the game that includes no competition.

\subsection{Research model and hypotheses}

Table 1 summarizes main hypothesis and supporting evidences of the study. Fig. 3 illustrates the hypothesized cause and effect relationship between competition, motivation, performance measures in the game and learning outcomes. Accuracy is calculated as the number of total correct answers to the questions in the game. The response time is regarded as the average duration that the player spends for reading the statement and providing the response for it. Accuracy and response time were calculated and recorded by the game itself.

The motivation of students during the game was assessed by a Turkish version (Acar, 2009) of the instructional materials motivation survey (IMMS) (Keller, 1993). Learning through the game was measured by the post-test test that was administered after the game play. The post-test includes items related to the game content.

\section{Results}

An independent samples $t$-test was performed to compare prior knowledge of participants in the competition and control groups. The results suggested that there was no difference in prior knowledge between the groups, $t(140)=0.36, p=.72$ (competition group: $M=7.86$, $S D=3.80$; control group: $M=8.11, S D=4.50)$. In order to compare post-test scores of the competition and the control group, a separate independent samples $t$-test was conducted. The results indicated that the competition group $(M=24.47, S D=8.93)$ performed better in the post-test than the control group $(M=20.92, S D=7.81), t(140)=-2.51, p=.01$.

Separate independent samples $t$-tests were run to investigate whether the groups differed in total reading time of explanations, total response time of answering to questions, and accuracy in the game. The results revealed that there was no significant difference between the groups in total reading time of explanations, $t(140)=-0.70, p=.49$, and in accuracy in the game, $t(140)=-.74, p=.46$. However, the competition group $(M=165.65, S D=92.77)$ spent more time on responding to the questions in the game compared to the control group $(M=137.02, S D=82.42), t(140)=-1.93, p=.05$. Another $t$-test was conducted to compare motivation of participants of the two groups. It was found that the participants in the competition group $(M=136.26, S D=18.94)$ had higher motivation than ones in the control group $(M=129.76, S D=18.03), t(140)=-2.09, p=.04$.

A two-way between-groups analysis of variance (ANOVA) was conducted to examine the effect of gender on post-test, as well as the interaction between gender and group. There was no significant main effect of gender on post-test scores, $F(1,138)=0, p=.98$. The interaction between gender and group did not reach statistical significance, $F(1,138)=1.29, p=.26$. Unequal sample size of female and male participants in competition and control groups should be also considered ( 32 females in competition group, 30 females in control group, 39 males in competition group, and 41 males in control group).

Table 1

Hypotheses and supporting evidences.

H1: Competition is positively related to motivation (Burguillo, 2010; Julian \& Perry, 1967; Malone \& Lepper, 1987; Nemerow, 1996; Yu, 2000)

H2: Motivation is positively related to accuracy in the game during learning (Toups, Kerne, \& Hamilton, 2009)

H3: Motivation is positively related to the response time to questions in the game during learning (Beck, 2004).

H4: Accuracy in the game is positively related to the post-test (Shin, Arbor, \& Soloway, 2006).

H5: The response time to questions in the game is positively related to the post-test (Eagle \& Barnes, 2009)

H6: Competition is positively related to the post-test (Johnson, Johnson, \& Stanne, 1985)

H7: Motivation is positively related to the post-test (Liu \& Chu, 2010) 
H6

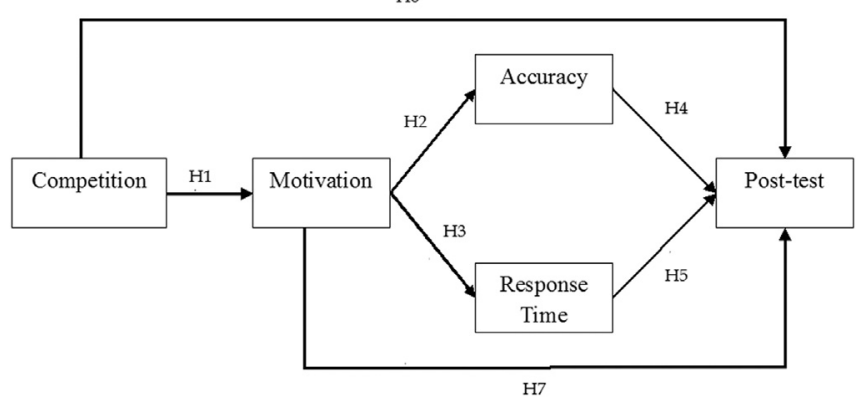

Fig. 3. Hypothesis of the study.

Pearson correlation analyses were performed to evaluate the relationship between the measures used in the study (see Table 2 for zeroorder correlations). Total reading time of explanations, motivation, total response time of answering to questions and accuracy in the game were positively correlated with post-test scores. For instance, it can be concluded that the more time spent on reading the explanations in the game, the better performance scores were obtained in the post test. Total response time of questions and accuracy in the game were significantly correlated with total reading time of explanations in the game. On the other hand, no significant correlation was observed between motivation and total reading time of explanations. Higher accuracy in the game but not motivation scores was associated with higher response time of questions. Lastly, higher motivation was related to higher accuracy in the game.

To test the proposed causal model presented in Fig. 3, a path analysis was conducted with LISREL 8.8 (Jöreskog \& Sörbom, 1997). The hypothesized relationships among the variables were shown in Fig. 3. The following fit indices, Goodness-of-Fit Index (GFI) $=.97$, the Comparative Fit Index $(\mathrm{CFI})=.90$, the Standardized Root Mean Square Residuals (SRMR) $=0.08$, Incremental Fit Index (IFI) $=.90$, and Normal Fit Index $(\mathrm{NFI})=.87^{1}$ indicated that the fit of the hypothesized model was acceptable.

Squared multiple correlations showed that the hypothesized model explained $32 \%$ of the variance in the post-test. The standardized parameter estimates (see Fig. 4) were calculated using LISREL's Maximum Likelihood Technique. These parameter estimates indicate change in a dependent variable associated with a unit change in an independent variable (Olobatuyi, 2006). For instance, a one standardized score increase in motivation is associated with .20 standardized score increase in accuracy in the game. The sign of the parameter estimate specifies the direction (negative or positive) of the relationship between the variables. When the sign is positive, both dependent and independent variables increase or decrease together. When the sign is negative, a variable increases while the other decreases. Parameter estimates having t-value greater than 1.96 were considered as significant at $\mathrm{p}<.05$, two-tailed (Tabachnick \& Fidell, 2001). Accordingly, competition was positively related with motivation $(t=2.09)$, thus $\mathrm{H} 1$ was supported. Motivation was positively associated with accuracy in the game $(t=2.43)$, but not with response time of answering to the questions in the game $(t=0.34)$. These results support H2, but not H3. Post-test was positively correlated with accuracy $(t=6.17)$ and response time $(t=3.20)$, supporting H4 and H5. However, the paths from competition to post-test $(t=1.78)$ and from motivation to post-test were not significant $(t=1.89)$. Hence, H6 and H7 were not supported. The path analysis (see Fig. 4) that examined the causal relationships among the variables revealed that competition enhanced motivation of participants and consequently increased accuracy in the game. As a result, better performance was observed in the post-test.

\section{Discussions}

Consistent with the literature (e.g., Burguillo, 2010; Julian \& Perry, 1967; Malone \& Lepper, 1987; Nemerow, 1996; Yu, 2000), the results of this study showed that competition in games enhanced learning and motivation of the participants. Participants in the competition group devoted more of their time to responding to the questions in the game than the ones in the control group. However, there was no significant difference between the groups in total reading time of the explanations and accuracy in the game. Gender had no effect on learning. Correlation analysis showed higher post-test scores were associated with higher motivation, more time spent on responding to questions and reading explanations, and higher accuracy in the game. Response time of questions and accuracy in the game were positively correlated with reading time of explanations in the game. The correlation results suggested that the more time spent on responding to the questions in the game, the more accuracy was observed in the game. Motivation was positively related to accuracy. On the other hand, no significant relationship were found between motivation and total reading time of explanations, as well as between motivation and total response time of questions.

To examine the causal relations between the observed variables, a path analysis was performed. The hypothesized structural equation model showed acceptable fit to the data. The results of the path analysis suggested that the competitive environment motivated learners and consequently this improved accuracy in the game which in turn increased post-test scores. Although, the causal path from motivation to response-time was not significant, the data showed that time spent on answering the questions in the game was positively associated with post-test performance. The more time participants spent on answering the questions, the better scores were obtained in the post-test. However, the paths from motivation to response-time in the game (H3), from competition to post-test (H6), and from motivation to post-test (H7) were not statistically significant. These results indicated that motivation was not associated with response-time, and competition and motivation were not related with post-test.

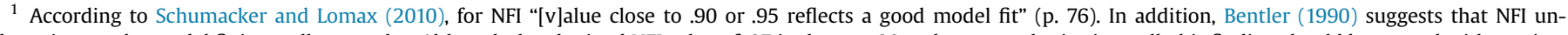

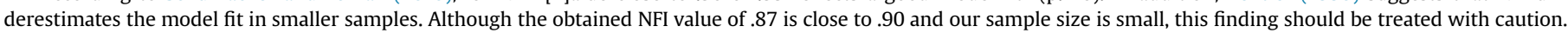


Table 2

Zero-order correlations for post-test, motivation, and behavioral measures in the game.

\begin{tabular}{|c|c|c|c|c|c|}
\hline Variable & 1 & 2 & 3 & 4 & 5 \\
\hline 1. Post-test & - & & & & \\
\hline 2. Total reading time of the explanations & $.17^{*}$ & - & & & \\
\hline 3. Total response time to the questions & $.32^{* *}$ & $.36^{* *}$ & - & & \\
\hline 4. Accuracy in the game & $.51^{* *}$ & $.20^{*}$ & $.22^{* *}$ & - & \\
\hline 5. Motivation & $.25^{* *}$ & -.07 & .02 & $.20^{*}$ & - \\
\hline
\end{tabular}

Note. ${ }^{*} \mathrm{p}<.05$

${ }^{* *} \mathrm{p}<.01$.

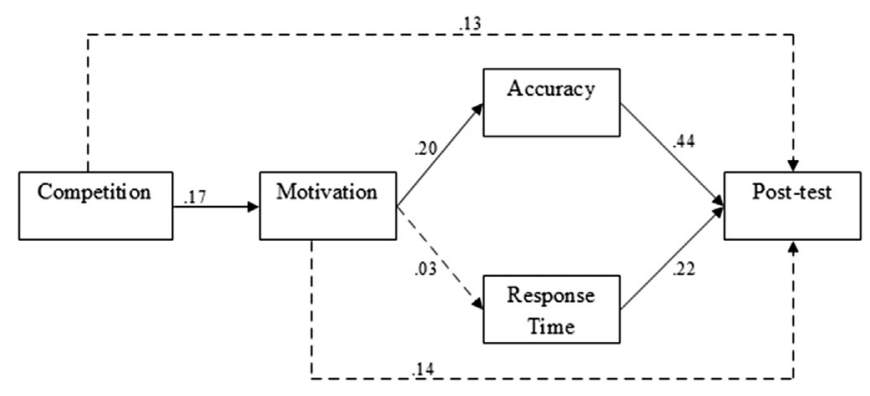

Fig. 4. Results of the model with standardized path coefficients.

Vandercruysse et al. (2013) found no effect of competition on learning outcomes and motivation. In contrast of the results of the study conducted by Vandercruysse et al. (2013), the results of this study show that when a competition environment is created in serious games, motivation and learning outcomes through the game improved significantly. Main reason for this difference could be the type of competition provided in the game. Our game is designed for creating a competition environment among the students where Vandercruysse et al. (2013) have designed the competition environment as an element of competing against a virtual opponent. Hence competing with other gamers other than a virtual opponent could be a factor affecting the gamers' motivation, accuracy and learning in games which is also supported by the earlier studies. For instance, Williams and Clippinger (2002) report that when participants played against a humancontrolled opponent, they experienced higher presence of flow and enjoyment than the ones who played against a computer-controlled opponent.

\section{Conclusions}

There is a gap of common understanding of the constituting elements of serious games for their effectiveness (Vandercruysse et al., 2013). The results of the current study suggest that adding the gaming element of competition to a game-based learning environment improves learning outcomes and motivation of participants. As a result, game designers should incorporate the element 'competition' to the games they created to facilitate learning.

Providing all challenging dimensions in a single game is not always possible. On the other hand, there may be some design features that relatively affect each other. For instance, some studies show that cooperation is more effective than competition in games while competition facilitates only cognitive achievement but not learning attitudes (Ke \& Grabowski, 2007). Future studies may also need to consider the relative effect of game design features in a systematical way. A limitation of this study is the small sample size for the path analysis and the sampling method (i.e., convenience sampling). Thus, the results of the current study need to be validated in a larger sample size and in different learning domains as well as with different age groups.

\section{References}

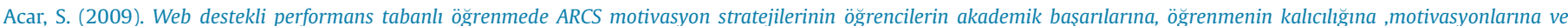
tutumlarma etkisi. Unpublished doctoral disseration. Turkey: Gazi University.

Andresen, G., \& Ahdell, R. (2002). Games simulation in corporate e-learning. Master thesis.

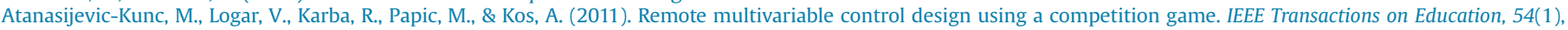
97-103.

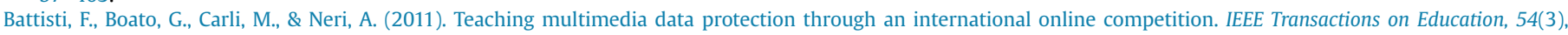
$381-386$.

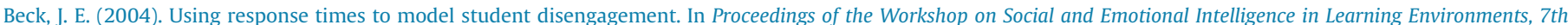
International Conference on Intelligent Tutoring Systems, Maceio, Brazil.

Bentler, P. M. (1990). Comparative fit indexes in structural models. Psychological Bulletin, 107(2), 238.

Burguillo, J. C. (2010). Using game theory and competition-based learning to stimulate student motivation and performance. Computers \& Education, 55, 566-575.

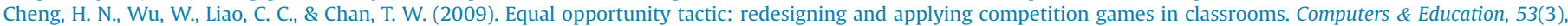
$866-876$.

Cruickshank, D. R., \& Telfer, R. (1980). Classroom games and simulations. Theory Into Practice, 19, 75-80.

Csikszentmihalyi, M. (1975). Beyond boredom and anxiety. San Francisco, CA: Jossey-Bass.

Csikszentmihalyi, M. (1990). Flow: The psychology of optimal experience. New York: Harper Row.

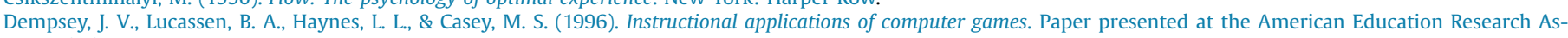
sociation, NY. 


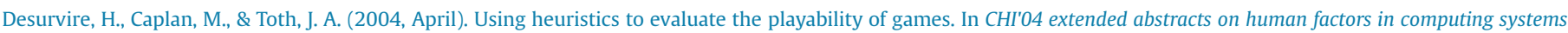
(pp. 1509-1512). ACM.

Dondlinger, M. J. (2007). Educational video game design: a review of the literature. Journal of Applied Educational Technology, 4(1), 21-31.

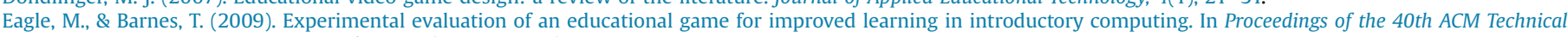
Symposium on Computer Science Education (pp. 321-325).

van Eck, R. (2006). Digital game-based learning: it's not just the digital natives who are restless. EDUCAUSE Review, 16-30. March/April.

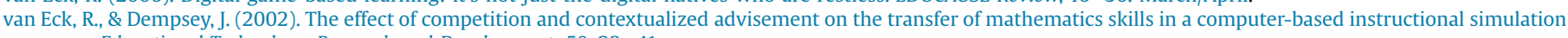
game. Educational Technology, Research and Development, 50, 23-41.

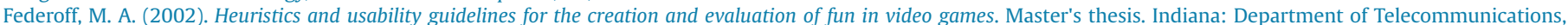
Master of Science. Indiana University.

Gee, J. P. (2004). Situated language and learning: A critique of traditional schooling. Psychology Press.

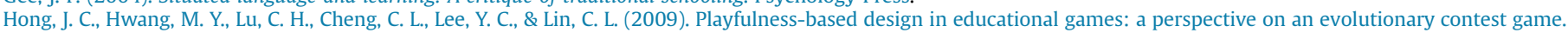
Interactive Learning Environments, 17(1), 15-35.

Howard-Jones, P. A., \& Demetriou, S. (2009). Uncertainty and engagement with learning games. Instructional Science, 37, 519-536.

Iuppa, N., \& Borst, T. (2007). Story and simulations for serious games: Tales from the trenches. NY: Focal Press.

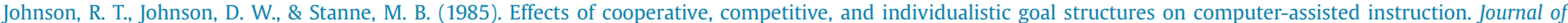
Educational Psychology, 77(6), 668-677.

Johnson, D., \& Wiles, J. (2003). Effective affective user interface design in games. Ergonomics, 46(13/14), $1332-1345$.

Jöreskog, K., \& Sörbom, D. (1997). LISREL 8.20 for windows. Lincolnwood, IL: Scientific Software International.

Julian, J., \& Perry, F. (1967). Cooperation contrasted with intra-group and intergroup competition. Sociometry, 30, 79-90.

Juul, J. (2005). Half-real: Video games between real rules and fictional worlds. Cambridge, MA: MIT Press.

Ke, F., \& Grabowski, B. (2007). Gameplaying for maths learning: cooperative or not? British Journal of Educational Technology, 38, 249-259.

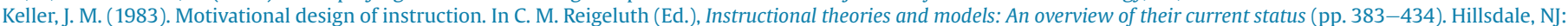
Erlbaum.

Keller, J. M. (1993). Manual for instructional materials motivational survey (IMMS). Tallahassee, USA.

Kohn, A. (1992). No contest: The case against competition. New York: Houghton Mifflin.

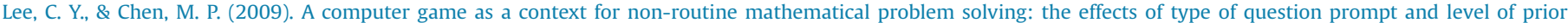
knowledge. Computers \& Education, 52(3), 530-542.

Lepper, M. R., \& Cordova, D. L. (1992). A desire to be taught: Instructional consequences of intrinsic motivation. Motivation and Emotion, 16, $187-208$.

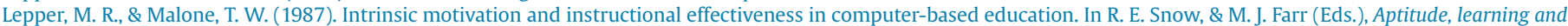
instruction: III. Cognitive and affective process analysis (pp. 255-286). Hillsdale, NJ: Erlbaum.

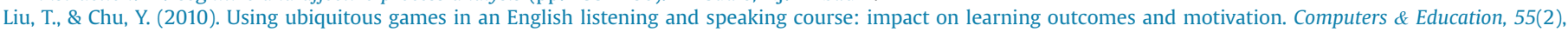
630-643.

Malone, T. (1981). Toward a theory of intrinsically motivating instruction. Cognitive Science: A Multidisciplinary Journal, 54, 333-369.

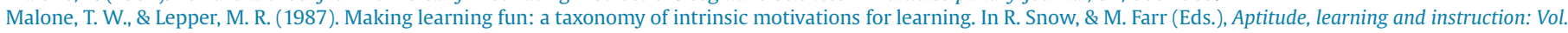
3. Cognitive and affective process analysis (pp. 223-253). Hillsdale, NJ: Erlbaum.

Nemerow, L. G. (1996). Do classroom games improve motivation and learning? Teaching and Change, 3(4), 356-366. University of Illinois.

Olobatuyi, M. E. (2006). A user's guide to path analysis. Oxford: University Press of America, Inc.

Ozcelik, E., Cagiltay, N. E., \& Ozcelik, N. S. (2013). The effect of uncertainty on learning in game-like environments. Computers \& Education, 67, 12-20.

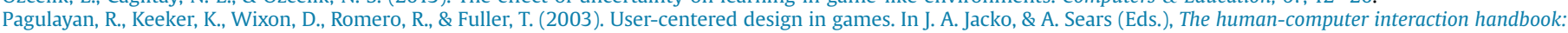
Fundamentals, evolving techniques and emerging applications (pp. 883-905). Mahwah, NJ: Lawrence Erlbaum Associates.

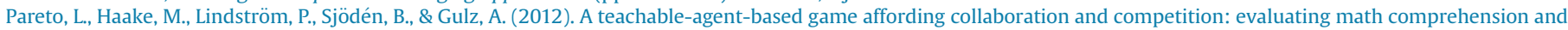
motivation. Educational Technology Research and Development, 60(5), 723-751.

Parker, L. E., \& Lepper, M. R. (1992). Effects of fantasy contexts on children's learning and motivation. Journal of Personality and Social Psychology, 62, 625-633.

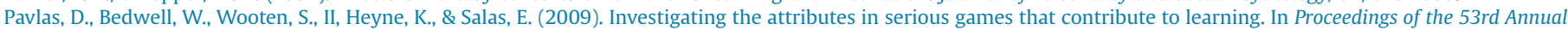
Meeting of the Human Factors and Ergonomics Society. San Antonio, TX.

Rouse, R. (2005). Game design: Theory \& practice. Plano, TX: Wordware Publishing, Inc.

Schumacker, E. S., \& Lomax, R. G. (2010). Structural equation modeling. New York: Routledge, Taylor \& Francis Group.

Shaffer, D. W. (2006). How computer games help children learn. New York, NY: Palgrave Macmillan.

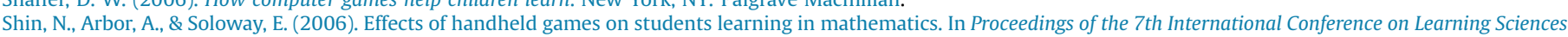
(pp. 702-708).

Sweetser, P., \& Wyeth, P. (2005). GameFlow: a model for evaluating player enjoyment in games. Computers in Entertainment (CIE), 3(3), 3-3.

Tabachnick, B. G., \& Fidell, L. S. (2001). Using multivariate statistics. Needham Heights, MA: Allyn \& Bacon.

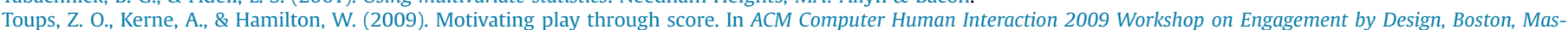
sachusetts, USA, April 4-9.

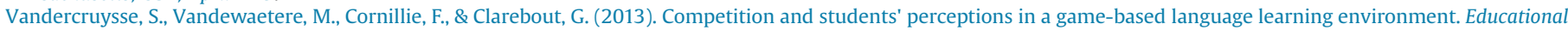
Technology Research and Development, 61(6), 927-950.

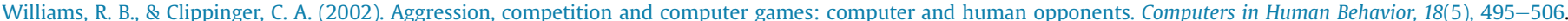

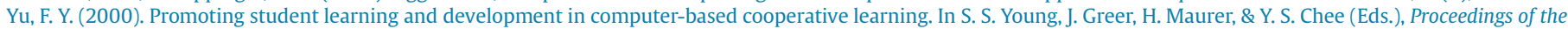
International Conference on Computers in Education/International Conference on Computer-Assisted Instruction (ICCE/ICCAI) (pp. 248-253). Taiwan. 